\title{
Reinsurance and Natural Disasters
}

\author{
by Nigel J. Thorne*
}

For the sake of clarity the term " natural disaster" or " natural catastrophe " needs to be defined. In simple terms the words " any sudden, severe, unexpected and fortuitous happening of a natural origin causing great damage to property and/or loss of life "will suffice for the present. For reinsurance purposes, the above comment requires qualification in terms of involvement of individual (insurance) risks, and limits of time and geographical area are also important. A perfect definition to cater for all eventualities relevant to reinsurance has yet to be devised, but is presently the subject of much discussion in the London market.

The incidence of natural disasters, as they affect all aspects of human existence, but particularly the insurance and reinsurance industry, has been the subject of increasingly close and searching study during the past ten years. I do not believe that this is due to any long term marked world-wide increase in the manifestation of the various types of natural disaster, although statistics may prove me wrong, but rather the increasing impact which some disasters seem to be having. In reinsurance terms, increasing exposure to loss is the key factor.

The perils with which the reinsurance industry is mainly concerned are the following:

- Earthquake / Volcanic Eruption / Tsunami

- Hurrican/Typhoon

- Tornado

- "Lesser windstorm"

- Flood

- Inundation

- Hail

- Snow / Frost / Severe weather

- Bush fire

- Fire Catastrophe - Conflagration (following earthquake)

- (Multiple Accident)

Such catastrophes or "events" as the reinsurance industry terms them, have been occurring for as long as mankind has been observing and in some cases suffering them. One of the earliest recorded earthquakes destroyed the city of Antioc in Syria with the

* Assistant Manager, The Mercantile \& General Reinsurance Company plc, London. 
loss of about 250,000 lives in $\mathrm{AD} 859$, whilst the earliest catalogued flood disaster happened in Babylon in 4000 BC. A steady and depressing succession of all examples of natural catastrophes has taken place over the centuries up to the advent of insurance and later on reinsurance arrangements as we now know them, and continues without respite to the present day.

So the catastrophes themselves are nothing new, and I feel that other reasons, which may be summarised as follows, at least partly explain this quickening of interest :

1. There is nothing like a series of financial losses to make any industry sit up and take notice, and the succession of catastrophes which occurred during the early and mid-seventies was something of a springboard in this respect. The most outstanding events from a reinsurance viewpoint were as follows, using uninflated figures :

\begin{tabular}{llll} 
Event & & Total Loss & Insured Loss \\
\hline Managua Earthquake & 1972 & $\$ 800$ million & $\$ 90$ million \\
Cyclone Tracy & 1974 & $\$ 500$ million & $\$ 300$ million \\
Guatemala Earthquake & 1976 & $\$ 1,100$ million & $\$ 150$ million
\end{tabular}

Many other events of considerable significance have occurred during this period, two of the most important being the Brisbane floods of 1974 and the European storms of 1976 (otherwise known as the Capella gale). However, the catastrophes which I have highlighted with figures demonstrated that very large losses could be sustained by insurers and reinsurers from what, on an international scale, are relatively small insurance markets, or concentrations of accumulation. Certainly Darwin, struck by Cyclone Tracy, a town of no more than 45,000 people, illustrates this point rather dramatically. Looking back, it may be fairly stated that many risk carriers were unpleasantly surprised by the size of the losses simply because adequate information regarding the accumulation of insured values exposed to one event was not available. It requires little thought to imagine the scale of insured loss which might be generated by a major earthquake striking much larger cities, such as Mexico City, Kingston or Caracas, to say nothing of the even more obvious areas of loss potential such as California or Japan. Furthermore, as a reinsurer, I feel that we should pay particular attention to the catastrophes where, but for the market practice and insurance mentality of potential policyholders, there would have been further extreme losses to our industry. I am referring here to the tragic earthquake in Italy, Algeria and Greece in recent years, and the inference is that very few policyholders purchased earthquake cover.

2. There has been a steady real increase in insured values exposed to natural perils throughout the world over and above the local rate of inflation, and normal business development, due to several factors :

(a) A greater demand by the insuring public for protection against natural hazards. A number of factors contribute to this, including higher standards of education generally, keener insurance awareness, and widening of policy cover due to demand and competition. Furthermore, in a world where more information and news is disseminated at greater speed, every natural disaster is given quicker and better publicity.

(b) The world's population continues to increase quickly, although less so in industrialised countries. Generally speaking, it must follow that there will be an enhanced demand for personal accommodation and associated facilities regardless of other factors. 
(c) In recent years it has been noticed that an increasing number of national prestige projects, in many cases funded or assisted from abroad, have been undertaken by what may be described as developing countries. These include steelworks, power stations, airport complexes, housing schemes, shopping plazas and the exploitation of mineral wealth.

(d) The dramatic increase in the sheer size and complexity of many projects and products, such developments often being vastly bigger in loss potential than, say, twenty years ago. This aspect is further aggregated by the variety of potentially dangerous processes and chemical reactions carried out in many manufacturing operations today.

(e) The trend, caused by shortage of land, to build in areas which have hitherto been considered unsuitable for one reason or another. Building in regions susceptible to flooding, landslide, subsidence, inundation by the sea, reclaimed land and regions comprising man-made fill, all fall into this category. To these vulnerability aspects should be added the (laudable) efforts to produce cheap, quickly realised housing accommodation, which may be intrinsically susceptible to damage.

These features clearly indicate why more importance is now, and must continue to be, attached to the monitoring of actual amounts of liability accumulation and ways of evaluating the size of the potential loss which may arise.

At this stage, it is worth reminding ourselves of the order or chain of business relationship which exists between Insurers, Reinsurers and Retrocessionaires, which has been commented on in another paper. A brief analysis of the reinsurance market's role demonstrates that it is essentially one of absorption of peak risks in terms of size and exposure, and of losses involving many risks in one event. Viewed another way, this absorption performs the function of smoothing out claims experience. In either sense, whether the reinsurer is a catastrophe treaty underwriter or proportional treaty underwriter (or both), he is exposed to the major part of all large risks whether they are individually or collectively "large ". Similarly, the increase in exposures referred to above tends to fall more heavily on the reinsurance market at the end of the day.

It is one thing to be aware of trends but quite another to be able to quantify their effects and significance in everyday terms. Reinsurers have been inadequately informed, for the most part, about the accumulation of risks exposed to one event. One of the reasons for this has been the advent of what is sometimes called the "blind treaty", which evolved quite a number of years ago when the decline in the preparation of treaty bordereaux began. Until that time reinsurers had the means, if not the inclination, to analyse risk by risk the business ceded to a treaty and establish its geographical spread, and the type of business and insurable interest. This enabled zonal aggregate exposure to be ascertained, at least in theory.

The blind treaty does not allow this and all that may be known by the reinsurer is the following, even after quite close investigation :

1. Class - For example "All business written by the Reinsured in its Fire Department" - subject to certain (brief) exclusions.

2. Territorial Scope - For example, "World-wide excluding U.S.A. and Canada" or "Middle East and Indian Sub-continent" or "Africa Only and incidental extensions". 
3. The maximum liability or capacity of the treaty on the best class of risk, plus scaling down if any by the table of limits.

4. A rough idea of geographical spread by historical data (if an established portfolio) relating to fire and perils premium combined.

5. Some insight into the ceding company's underwriting policy and plans and its emphasis as to type of business written, e.g. whether commercial/industrial or personal lines only, and its general attitude to marketing.

6. Claims if any experience of fire business, and perhaps natural perils.

Naturally, a long established direct relationship between reinsurer and Insurance company will tend to avoid such short-comings, whilst the presence of an intermediary may exacerbate the situation. However, the reinsurer will, in most cases, have little idea of those many (perhaps thousands) risks in the mix of business ceded to a treaty, which are exposed to loss by one event, and their total insured value at any one time. Multiply this factor by the number of proportional treaty connections in which the reinsurer may participate from one market, not forgetting shares in world-wide proportional contracts which may also have cessions from that same market, and it becomes obvious that potential loss assessment is a major difficulty. Excess of Loss treaties, although having finite limits, contribute further to this problem.

In essence, therefore, there are two main aspects to the reinsurer's problem:

1. Having, and being able to analyse, sufficient information to quantify the risk of occurrence of a natural catastrophe and the degree of damage it may cause, and frequency thereof.

2. Receiving sufficient information from insurance companies, where relevant, to apply the findings under 1 above to the portfolio of business in question in order to price a suitable reinsurance protection.

Time permits me to deal with one peril only, and that of earthquake will serve as a good example. In order to illustrate the overall complexity of the first factor above, it is useful to consider the potential multiplication of uncertainty presented by the following interplay :

Earthquake

- Frequency (return period)

- Severity

- Depth of Focus

- Direction (relating to insured values)

- Distance (from insured values)

Geology

- Proximity of fault line

- Type of surface soil

- Depth of surface soil

- Compressibility of surface soil

- Degree of water content

Buildings

- Design

- Height 
- Standard of materials

- Type of construction

- Standard of construction

- Occupation

- Probability of fire spread

You may read from the other excellent contributors here of the efforts which are being made to improve our knowledge in the above matters, both individually and integrally. In my opinion, there remain large areas, especially that of the earthquake risk itself, where more experience is required. Similar considerations apply, generally to a lesser degree, to the other natural perils.

With regard to the second point, it is possible for insurance companies to devise methods of monitoring the business ceded to their Quota Share and Surplus treaties and also that retained for net account. The modus operandi of the Quota Share and Surplus arrangements (proportional treaties) has been explained, but one of the major methods of reinsuring the net account, i.e. the proportion of those insurance acceptances which an insurance company either does not need to reinsure in the Quota or Surplus fashion, or retains after such cessions, is the Excess of Loss treaty, known as the catastrophe cover of " event" cover.

The purpose of this protection is to limit a loss suffered by an insurance company (net account) from an aggregation of claims arising out of the same event (hence "event" cover) or fire. The cover is, therefore, in addition to and not a substitute for the proportional reinsurance. Definition of an event is required.

The point at which the excess of loss cover commences (variously known as " excess point", "deductible" or "priority") may be defined as equal to or greater than the amount retained, EML basis where applicable, by the insurance company on one risk. Catastrophe protection generally commences in excess of two or more maximum net retentions for any one risk. The excess point should also:

(a) generally represent between two per cent and five per cent of the insurance company's premium income generated by retained shares or risks. This ensures reasonable financial involvement of the company in the loss before reinsurers pay for the remainder;

(b) not exceed a modest proportion of the ceding company's capital and free reserves. This is critical in early years of development ;

(c) have regard to the retained exposures in respect of natural perils. If such exposure is negligible for whatever reason, the catastrophe cover should be constructed to cater for Fire Conflagration risk only.

With regard to the limit of cover required, the same features apply in that :

(a) this would not normally be more than two to three times the retained premium income ;

(b) would not normally exceed 100 to 150 times the net retention per risk;

(c) would depend very largely upon natural peril exposure, where this is significant. It is necessary for the limit to be at least as high as the maximum loss from the expected event that the net account may suffer in the territory or zone in question. 
Costing of such a protection is normally carried out by charging a fixed rate per cent on the estimated net retained income, thus producing a premium for the year. This is adjusted at the end of the year on the actual retained income. At this stage, it should be noted that catastrophe programmes of any size are split into two or more layers when being priced and placed. Determining the cost of these layers must take into account the following :

1. The size of the deductible in relation to the insurance company's maximum net retention per risk, and retained premium income. The smaller the deductible compared with these items, the more exposed is the layer and the greater its cost.

2. The amount of cover being purchased in relation to the foregoing items in 1. above.

3. The size of deductible and cover compared with the aggregate of sums insured exposed to natural perils in the principal territory or region.

4. The expected frequency of (natural peril) losses to the layers of protection.

5. Previous relevant claims experience, if any.

One can now understand how a recurrent theme in the placing and pricing of a catastrophe programme involves, inter alia, knowledge of :

(a) the total of sums insured retained by an insurance company exposed to one event allied to;

(b) the size or severity and return period of the "maximum probable event", however this may be deduced;

(c) the degree of damage which this maximum probable event will cause to the account protected ;

(d) the frequency and degree of damage likely to be caused by (more frequent) small events affecting the lower layers of the programme.

It seems that points (b), (c) and (d) must be entrusted to the disciplines of seismology, geology, meteorology and engineering.

As for point (a) above, the gathering of actual insurance accumulation statistics is an art for the insurer and the reinsurer to perfect. As reinsurers we believe that we know what we want and Dr. Porro has already drawn attention to the fact that efforts have been in progress to achieve this end for a number of years. I endorse his implied observation that considerable improvement is still needed in this respect, partly because some insurance companies are ill-equipped or unwilling to produce proper statistics, and partly because of the less technically orientated elements of the world-wide reinsurance market, which is still suffering from apparent over-capacity.

The practical consequences of having too little information may be briefly summarised as follows :

1. At worst, the occurrence of one or more natural catastrophes in a limited period in areas where a reinsurer is unwittingly too heavily committed could lead to its financial ruin, and thus place in jeopardy the very insurance companies it is supposed to be protecting. One should bear in mind that such losses would accumulate with what might also be bad experience in other lines of related business.

2. At best, the reinsurer is unable to use safely its capacity to the full, and is improperly equipped to decide how much business to accept, how much to retrocede and how 
much excess of loss protection to purchase. As far as direct insurance is concerned, the insurance company itself is faced with similar difficulties at one stage removed, and may be obliged to load the cost of the service they provide as a financial safety measure, and curtail available capacity by the same token.

It must be stressed that any efforts to glean information about accumulation of risk will ultimately be of as much benefit to the insurer, and therefore the policyholder, as to the reinsurer.

Clearly it must be a fundamental aim to mitigate the direct effects of natural catastrophes on human lives and property. Historical, economic and environmental factors have left a legacy of many principal cities being located in regions which, from the natural perils viewpoint, are thoroughly unsuitable. It is impractical to suggest that such populations are moved en mass, but it is certainly feasible to encourage positive avoidance of areas at risk where new construction and development is concerned.

Insurance companies have a vested interest, at the earliest stage, in attempting to establish some sort of organised dialogue and collaboration between landowners, architects, scientists, designers and engineers, building contractors, building education and supervisory authorities and relevant government departments. Such liaison, whilst probably difficult to achieve, must be realised in order to reduce the risk and degree of loss at the outset. Any success in this respect would serve to relieve financial loss to the reinsurance industry.

One obvious but not particularly palatable means of reducing costs to insurers and reinsurers is to involve the original policyholder in payment of a proportion of the loss. This follows the perhaps not unreasonable concept that individuals and profit making organisations ought to contribute something themselves (in addition to the premium) rather than be totally shielded from the financial consequences of serious catastrophes. There is considerable variation in practice world-wide, but most relevant policies are subject to a deductible borne by the policyholder, actual amounts varying considerably. This concept is sometimes extended by the imposition of a co-insurance factor, whereby the policyholder is required to bear a fixed percentage of any claim over and above the deductible. The percentage varies, but up to $25 \%$ is typical, for example, in Mexico.

Quite how policyholders would be able to respond to such a term remains to be seen ; personally I would find it financially impossible to foot the bill for a $2 \%$ deductible $+25 \%$ co-insurance of the rebuilding cost of my house were it destroyed by earthquake.

The Japanese insurance market has tried to solve their earthquake problem by dividing their policyholders into the private class which is protected by the Government backed Japanese Earthquake Reinsurance Company, and the industrial sector, which is insured privately on the limited indemnity basis. The proportion of earthquake protection which industrial policyholders can purchase varies from $15 \%$ to $60 \%$ of the fire sum insured, with the balance effectively self-insured. Reinsurance protection is placed world-wide and the limited indemnity concept is clearly a loss palliative for insurers and reinsurers. However, this leaves the nation open to the consequences of mass underinsurance.

The New Zealand scheme requires compulsory contribution of all (fire) policyholders to the Earthquake and War Damage Commission Fund, which protects the policyholders 
against damage to specified property by specified perils. Exhaustion of the fund implies Government involvement and any reinsurance protection which they may place in the world-wide market.

In other countrywide schemes, for example, Iceland and France, a greater or lesser extent of Government participation is either agreed or implied and it seems that the world-wide reinsurance market and governments should be prepared to collaborate in this field in the long term.

An aspect which should particularly benefit from scientific research and analysis, as well as joint attention from insurers, reinsurers and government departments, is the question of primary insurance rates for natural perils. Until fairly recently, the additional premiums charged for Fire policies so extended was included in the overall premium and accounted for on an inclusive basis. This meant that any annual profit commission payable has embraced such natural peril premium although this ought not to be considered as " profit" merely because of a loss-free year in this respect. Much improvement has been made in this context following steps by reinsurers to encourage separation of natural peril premiums which are then subject to lower commission rates, and which can now be quantified. However, the adequacy of such premiums has yet to be analysed in scientific terms in many territories, and this feature is further complicated by differing policy cover, and the ways and means of watering down original recommended tariff rates. These range from the "friendly discount", the discount for "bulk" purchase, widening of cover for no additional premium, or even straightforward waiving of such premium altogether. As reinsurers, we are aware that net rates for earthquake cover are sometimes as little as $20 \%-25 \%$ of the theoretically correct tariff figure, where one exists. The circumstances surrounding the insurance of natural perils, particularly the concept of long-term Fund building, make it clear that discounting the tariff, for commercial reasons or otherwise, must be avoided.

By way of summary, I would say that the reinsurance markets of the world do not know, with sufficient accuracy, when the next major catastrophe will occur, where it will strike, what degree of damage will take place, what the accumulated loss will be and when a similar event will happen again. To put it another way, if a reinsurer receives correct aggregate accumulation risk statistics for his portfolio of business in a key zone, what proportion of that amount will be lost, and how often? It is this great grey area, the intrinsic nature of natural perils, which leads some authorities to believe they are uninsurable. They do not, after all, obey the basic rule of insurance whereby "the premiums of the many pay for the losses of the few".

I prefer to believe that by removing as many of these avoidable areas of uncertainty as possible and by supporting the research of our seisemologists, engineers, meteorologists and physicists, who may ultimately reduce the earth's natural phenomena to quantifiable levels, we will be able to put the rating and insurance of the same, and the calculation of accumulation of risks exposed to them on a sound and certain basis. I feel sure that the work of the Seminar this week marks a further important step in the realisation of these goals. 